\title{
Psicologia da educação e as tecnologias digitais de informação e comunicação
}

\author{
Fabio Scorsolini-Comin \\ Universidade Federal do Triângulo Mineiro - MG
}

\begin{abstract}
Resumo
O objetivo deste estudo é discutir repercussões das Tecnologias Digitais de Informação e Comunicação (TDICs) no campo da Psicologia da Educação. O estudo é teórico e está amparado numa revisão narrativa da literatura científica que analisou diferentes fontes de evidência presentes em livros, artigos e simpósios. As publicações destacam a flexibilização de espaços como as salas de aula, a ocorrência dos processos de ensino-aprendizagem em diferentes locais e situações e a assunção de ambientes globais de aprendizagem, em que o desenvolvimento das tecnologias móveis e das redes sem fio amplia as possibilidades da prática pedagógica. Ressalta-se a importância do papel do professor na assimilação das TDICs pela Educação e no seu uso de modo reflexivo. Conclui-se que o escopo da Psicologia da Educação é suficientemente amplo para abarcar essas mudanças, mas ela deve produzir conhecimentos que possam contribuir no diálogo entre os saberes psicológicos, práticas educacionais e tecnologias digitais de informação e comunicação.
\end{abstract}

Palavras-chave: Psicologia educacional; educação à distância; tecnologia educacional.

\section{Educational psychology and digital information and communication technologies}

\begin{abstract}
In this study we aim at discussing the implications of digital information and communication technologies (DICT) in the context of Educational Psychology. This is a theoretical study supported in narrative review of the scientific literature that analyzed different sources of evidence present in books, articles and scientific events. The publications highlight that spaces such as classrooms are increasingly flexible, the occurrence of teaching and learning in different environments and the assumption of global learning environments in which the development of mobile technologies and wireless networks expands the possibilities of the educational practice. We emphasize the role of the teacher in the assimilation of DICT and its use in education reflexively. As a conclusion, the scope of Educational Psychology is enough to contemplate these changes, but it should produce knowledge that can contribute to the dialogue between the psychological knowledge, educational practices and digital information and communication technologies.
\end{abstract}

Keywords: Educational psychology; distance education; educational technology.

\section{Psicología de la educación y las tecnologías digitales de información y comunicación}

\begin{abstract}
Resumen
El objetivo de este estudio es discutir repercusiones de las Tecnologías Digitales de Información y Comunicación (TDICs) en el campo de la Psicología de la Educación. El estudio es teórico y está amparado en una revisión narrativa de la literatura científica que analizó diferentes fuentes de evidencia presentes en libros, artículos y simposios. Las publicaciones destacan la flexibilización de espacios como las salas de clase, la ocurrencia de los procesos de enseñanza-aprendizaje en diferentes locales y situaciones y la asunción de ambientes globales de aprendizaje, en que el desarrollo de las tecnologías móviles y de las redes sin cable amplía las posibilidades de la práctica pedagógica. Se hace hincapié de la importancia del papel del profesor en la asimilación de las TDICs por la Educación y en su uso de modo reflexivo. Se concluye que el mito de la Psicología de la Educación es suficientemente amplio para abarcar esos cambios, pero ella debe producir conocimientos que puedan contribuir en el diálogo entre los saberes psicológicos, prácticas educacionales y tecnologías digitales de información y comunicación.
\end{abstract}

Palabras-clave: Psicología de la Educación; educación a distancia; tecnologías educacionales. 


\section{Introdução}

$\mathrm{Na}$ cibercultura, a distância entre os campos do conhecimento é cada vez mais relativa, de modo que os saberes produzidos são considerados transitórios, haja vista que diferentes ferramentas e elementos são criados constantemente para facilitar, agilizar ou promover os processos de ensino-aprendizagem. Nesse novo modelo de compreender a relação entre pessoas e conhecimentos, aprender é uma tarefa cada vez mais importante, uma vez que as estruturas tecnológicas tornam-se obsoletas a cada dia, obrigando as pessoas a lidar com um repertório cada vez mais vasto de informações e de trânsito de dados, com informações que podem incluir ou excluir o sujeito de uma sociedade em rede.

Lidar com as Tecnologias Digitais de Informação e Comunicação (TDIC) não se torna apenas uma necessidade, mas também uma possibilidade de inserção em ambientes que fazem parte da vida cotidiana, de modo que dominá-las passa a ser uma forma de existir no mundo contemporâneo (Almeida, \& Silva, 2011; Joly, Silva, \& Almeida, 2012; Lévy, 2010). As tecnologias como mediadoras dos processos de desenvolvimento e de aprendizagem, tal como consideradas por teóricos como Vigotski, Piaget e Bakhtin, têm adquirido um caráter cada vez mais expressivo, de modo não apenas a instrumentalizar ou potencializar uma ação educativa ou desenvolvimental (Scorsolini-Comin, Inocente, \& Matias, 2009), mas também conferir a tal ação um sentido novo, uma função diferente: a de se comunicar no mundo contemporâneo e pertencer a essa nova malha de configurações.

Neste sentido, as TDIC têm se articulado a diferentes conhecimentos, entre eles os da Psicologia da Educação, diretamente relacionados aos processos educativos e psicológicos que ocorrem em situações de ensino-aprendizagem em diferentes contextos educacionais e de aprendizagem (Scorsolini-Comin, 2013). O papel dessas tecnologias na mediação desses processos e na caracterização desse campo do saber tem se tornado uma pauta premente nas agendas de psicólogos, educadores e outros profissionais relacionados, como, por exemplo, os gestores educacionais.

A partir desse panorama, o objetivo deste estudo é discutir as repercussões das Tecnologias Digitais de Informação e Comunicação no campo da Psicologia da Educação mediante uma revisão narrativa da literatura científica sobre as perspectivas da Psicologia da Educação, dado o contexto de integração das TDIC na Educação. São recuperados estudos importantes acerca do tema, priorizando uma discussão crítica e integradora sobre esse conjunto de conhecimentos produzidos e disponibilizados em materiais como livros, artigos, teses, dissertações, grupos de trabalho e simpósios (Rother, 2007), a fim de delimitar lacunas e potencialidades para futuras produções e reflexões (Witter, 2005).

Para organizar o estudo teórico e permitir a discussão a partir de diferentes momentos, este artigo está dividido em três partes. Na primeira delas abordaremos o conceito de TDIC. Em um segundo momento, apresentaremos o campo da Psicologia da Educação na contemporaneidade, discutindo alguns de seus objetos de estudo. Por fim, analisare- mos de que modo as TDIC têm repercutido na redefinição do escopo da Psicologia da Educação e como este campo tem dialogado com essas tecnologias para a promoção do desenvolvimento dos estudos na interface entre Psicologia e Educação.

\section{Das "velhas" às "novas" tecnologias aplicadas à educação}

Para atingir o objetivo proposto é preciso estabelecer o que compreendemos por essas tecnologias. Mais do que isso: quando assinalamos que se trata de novidades, podemos recuperar quais tecnologias tornaram-se obsoletas e podem ser consideradas velhas, notadamente no campo educacional. $\mathrm{Na}$ era do hiperconsumo, tal como discute $\mathrm{Li}$ povetsky (2007), as fronteiras entre velho e novo tornam-se tênues, de modo que a transição de uma condição a outra ocorre sem que, necessariamente, declaremos as distinções entre elas. $\mathrm{O}$ velho e novo também convivem e se redefinem constantemente, sendo um desafio conceituar o que se alinha a uma condição ultrapassada e aquilo que imprime um novo caráter a uma dada noção. Cada vez mais, o conceito de Novas Tecnologias da Informação e da Comunicação (NTIC) tem sido substituído pelo de Tecnologias Digitais de Informação e Comunicação (TDIC) (Almeida, \& Silva, 2011), reforçando que não se trata mais de novidades, haja vista que as tecnologias digitais são constantemente revistas e incrementadas, de modo que as noções são dinâmicas e o mundo é marcado pelo acelerado fluxo de transformações. As TDIC podem ser compreendidas como ferramentas versáteis presentes em diversos contextos que ultrapassam as possibilidades das tecnologias analógicas. Em comparação com estas, as TDIC "trouxeram benefícios, como facilidade de comunicação e acesso a um maior número de informações sobre assuntos em geral, mas também trouxeram problemas (...), como a necessidade de apropriação e inserção dos indivíduos neste contexto" (Joly, Silva, \& Almeida, 2012, p. 84). Nosso objetivo neste artigo é, portanto, compreender como as TDIC têm repercutido no campo da Psicologia da Educação.

Logo no início desse diálogo é importante destacar que o campo de aplicação da Psicologia da Educação não mais se estende exclusivamente aos ambientes físicos e materiais em que ocorre a aprendizagem - como escolas, universidades, instituições e hospitais (Maluf, 2010). Outro ambiente a ser considerado é o virtual, definido por Pierre Lévy (2010) como ciberespaço, local que proporciona a materialização da cibercultura. Para este autor, o ciberespaço (também compreendido como rede) é o "novo meio de comunicação que surge da interconexão mundial dos computadores" (p. 17) e a cibercultura é o "conjunto de técnicas (materiais e intelectuais), de práticas, de atitudes, de modos de pensamento e de valores que se desenvolvem juntamente com o crescimento do ciberespaço" (p. 17). Assim, podemos compreender a cibercultura tanto como a cultura operacionalizada no contexto atual das redes de computa- 
dores como o conjunto de práticas e valores que emergem de um novo modo de se relacionar com o conhecimento e com a informação.

É nesse contexto que as TDIC passam a figurar como ferramentas para a compreensão da informação nesse novo meio de interagir, trocar e aprender. As TDIC não promovem, por si sós, uma mudança radical no modo de conceber a aprendizagem ou a interação na cultura vigente, mas são consideradas técnicas cuja assunção foi possibilitada pela cibercultura, de modo que não determinam sozinhas as transformações observadas. Essa é uma consideração enfatizada por Lévy (2010) que promove uma primeira forma de apreciar as TDIC como um produto da cibercultura e não como um fator desencadeante das características que hoje se agrupam sob a égide da cibercultura. O ciberespaço ou a rede - que inclui a internet - promove um novo paradigma, ou seja, a internet passa a constituir um novo e complexo espaço global para a ação social, o aprendizado e a ação educacional (Castells, 2001).

$\mathrm{Na}$ sociedade do conhecimento, as relações interpessoais, educacionais e profissionais são descritas em meio às transformações de ordem política, econômica, social, cultural e histórica. Tais mudanças não podem ser compreendidas como passíveis de serem delimitadas com exatidão, mas mesclam-se na proposição de novas linguagens e formas de interação, inclusive com o conhecimento. Este vem sendo compreendido como um conjunto de saberes que não mais se alojam em determinados campos, mas que dialogam ininterruptamente, promovendo transformações e diferentes modos de ver e analisar os fenômenos humanos.

Nesse âmbito em permanente ruptura e reconstrução, as TDIC têm sido cada vez mais discutidas na área da educação em termos de sua adoção nos meios educacionais e de sua possibilidade de agilizar, facilitar e promover novas leituras de mundo em escolas e universidades. Conforme destacam Moreira e Kramer (2007), são atribuídos múltiplos sentidos à presença dessas tecnologias no ensino, entre os quais estão o de superação das consideradas "velhas tecnologias" (lousa de giz, materiais predominantemente impressos), de solução de problemas pedagógicos vivenciados pelos professores em sua prática cotidiana e questões sociais mais amplas, como as relacionadas à inclusão digital ou ao modo como as pessoas têm se relacionado com o conhecimento na era digital. Em muitos desses sentidos, as TDIC são consideradas uma renovação ou uma possibilidade de facilitação do processo de ensino-aprendizagem que se sustenta quase automaticamente nos recursos tecnológicos avançados que as constituem.

Não obstante, as TDIC devem ser compreendidas como uma produção histórico-social, e não como um incremento de qualidade aos processos anteriormente observados, como se a sua adoção fosse responsável pelas transformações (Moreira, \& Kramer, 2007; Patto, 2013). Quando falamos em TDIC não estamos, necessariamente, abordando a questão da qualidade do ensino, mas as potencialidades que essas tecnologias abrem para que os processos de ensino-aprendizagem sejam revistos, incrementados e transformados. Seu uso deve ser compreendido de modo crítico, e não como uma estratégia de mercantilização da Educação e de afastamento entre docentes e alunos (Patto, 2013; Pereira, 2009; Zuin, 2006). Muitos sistemas de ensino, por exemplo, "vendem" tais tecnologias como sinônimo de qualidade e inovação, desconsiderando o investimento na prática pedagógica, na figura do professor e em sua interação com os alunos.

Como referido por Coll e Monereo (2010) no tocante à avaliação da qualidade do ensino no contexto contemporâneo, nem tudo o que é tecnologicamente viável é pertinente em termos educacionais, e vice-versa, o que significa que as TDIC não devem simplesmente ser incorporadas sem uma adequada e profunda investigação acerca de suas necessidades, limites, possibilidades e consequências para o ato educativo. As atuais críticas aos modelos que empregam essas tecnologias referem-se, em sua maioria, à falta de reflexão acerca do papel docente, ao silenciamento da relação professor-aluno e à ênfase na distância, não nos recursos que possam aproximar alunos e professores de uma relação pedagógica considerada satisfatória. No Brasil ainda se importam muitas tecnologias e metodologias estrangeiras, por exemplo, as europeias (Coll, \& Monereo, 2010), de modo que é preciso construir modelos (e, consequentemente, tecnologias educacionais) que considerem nosso contexto e suas particularidades, no tocante tanto às características dos alunos, dos professores e do ensino, como ao acesso às tecnologias (Joly, Silva, \& Almeida, 2012).

Em termos da evolução das tecnologias aplicadas à educação, Coll e Monereo (2010) destacam a passagem dos ambientes naturais ( $1^{\circ}$ momento), com predomínio da linguagem oral, para o artificial $\left(2^{\circ}\right.$ momento), em que predominava a escrita e, por fim, o ambiente virtual ( $3^{\circ}$ momento), em que predominam as linguagens analógica e digital. Nesse último e mais recente ambiente psicossocial, recriam-se meios de comunicação e desenvolvimento para responder aos desafios da globalização. Entre as tecnologias de comunicação estão o telefone, o telégrafo, a multimídia e a internet. $\mathrm{Na}$ internet, observamos a transição da Web 1.0 (rede de documentos), passando para a 2.0 (rede social) e chegando a 3.0 (rede semântica), o que radicaliza o modo não apenas de compreender a tecnologia, mas também de empregá-la na comunicação entre as pessoas. É neste sentido que as características da interação evoluem da representação simbólica dos interlocutores, passam pela interdependência espacial e temporal e chegan às ações síncronas e assíncronas.

As modalidades educacionais associadas ao meio virtual evoluem do ensino a distância (por exemplo, em cursos apostilados) para o ensino apoiado pelo computador, chegando ao e-learning (desenvolvido com o apoio da internet) e, mais recentemente, ao m-learning, uma modalidade de ensino que utiliza dispositivos móveis (como celulares e tablets) e conectividade sem fio para estabelecer comunicações entre vários agentes educacionais com uma finalidade instrucional (Coll, \& Monereo, 2010). O m-learning é conhecido como a escola nômade, haja vista que o ensino 
e a aprendizagem podem acontecer a qualquer tempo e em qualquer espaço, o que amplia as possibilidades de realização de trabalhos de campo, análise conjunta de atuações profissionais e reflexões.

Nesse novo cenário, algumas características discutidas por Coll e Monereo (2010) podem ser destacadas, como complexidade, interdependência, imprevisibilidade, informação, excesso de informação e de ruído, rapidez dos processos e das suas consequências, cultura da imagem e do espetáculo, homogeneização cultural, surgimento de novas classes sociais ("inforricos" e "infopobres") e transformação das coordenadas espaciais e temporais da comunicação. Em meio a essas características é que o lugar da Psicologia da Educação deve ser debatido, como apontado a seguir.

\section{Qual o lugar (ou os lugares) da Psicologia da Educação na era das TDIC?}

A Psicologia da Educação é considerada uma das áreas mais tradicionais da ciência psicológica, sendo fortemente influenciada pela Filosofia. Frequentemente, esse termo é confundido com outros correlatos, como Psicologia Educacional, Psicologia da Aprendizagem, Psicologia Escolar, Psicoeducação, Psicopedagogia, Psicologia da Criança, entre outros, em um movimento que não é linear e isento de influências, mas justamente reflete questões epistemológicas, ideológicas e políticas (Barbosa, \& Souza, 2012).

Um termo recente em discussão é a Psicologia da Educação Virtual (Coll, \& Monereo, 2010), que contempla a produção de conhecimentos acerca da relação entre Psicologia e Educação no contexto da virtualidade e dos espaços midiáticos criados na cibercultura. Mais do que fazer distinção entre os termos e a necessidade de pontuar os diferentes objetos de estudo existentes nessa multiplicidade, é preciso considerar que, de fato, tais definições chocam-se constantemente, promovendo uma possibilidade de leitura que vai além dessas diferenças e priorizando o diálogo interdisciplinar. Segundo Gatti (2010), pesam sobre a delimitação desses conceitos os aspectos econômicos, políticos e acadêmicos, que esbarram em dificuldades anteriores de definição de Educação e também da Psicologia. Na tensão sobre o locus da Psicologia da Educação - se na Psicologia ou na Educação -, muitos aspectos ainda devem ser amadurecidos em face das dificuldades impostas pela interdisciplinaridade.

Longe de solucionar tal tensão, que acompanha a produção científica na área, pode-se afirmar que a Psicologia da Educação tem por objeto de estudo todos os aspectos das situações da educação, sob a ótica psicológica, assim como as relações existentes entre as situações educacionais e os diferentes fatores que as determinam. Seu domínio pode ser expresso pela análise psicológica de todas as facetas da realidade educativa e não apenas a aplicação da Psicologia à Educação (Coll, Palacios, \& Marchesi, 1996; Mialaret, 1999). Ainda, pode ser descrita como um esforço constante de utilizar princípios, explicações e métodos da Psicologia científica na tentativa de melhorar as práticas educativas em geral (Coll, Palacios, \& Marchesi, 1996). No entanto, tais definições ou descrições não estariam mais cristalizadas, mas submetidas permanentemente a um exercício de reescrita com base nas transformações observadas, entre elas o advento das tecnologias educacionais (Gatti, 2010). No que se refere a essa definição suficientemente ampla, considera-se que as TDIC não têm promovido a necessidade de redefinição do campo da Psicologia da Educação, mas sim de cotejar essas tecnologias e o modo como têm impactado o ato educativo nos estudos da área.

Bezerra e Araújo (2012) afirmam que na contemporaneidade há uma crise epistemológica na Psicologia da Educação, destacando que a reação negativa às contribuições da Psicologia da Educação observada na práxis pedagógica e na formação docente deve-se ao possível descrédito quanto ao paradigma construtivista-cognitivista, de inspiração piagetiana. A necessidade é de trazer para esse campo uma perspectiva crítica, reflexiva e emancipadora. Nesse campo de investigação, diferentes perspectivas teóricas têm sido empregadas, tais como a comportamental, epistemologia genética, psicanálise, Psicologia Histórico-Cultural, Teoria Crítica, das Representações Sociais, entre outras.

A análise dos textos apresentados no Grupo de Trabalho de Psicologia da Educação da Associação Nacional de Pesquisa e Pós-Graduação em Educação (ANPEd), no período de 1998 a 2008, por exemplo, revelou o predomínio do referencial histórico-cultural (Carvalho, Facci, \& Barroco, 2010), embora não haja qualquer menção às TDIC na interface Psicologia e Educação. A ausência dessa discussão também foi pontuada a partir da investigação de Schlindwein e Cordeiro (2010). Estas autoras, pensando nas perspectivas futuras no campo da Psicologia da Educação, elencam a possibilidade de ampliar a discussão sobre subjetividade, identidade e desenvolvimento do sujeito a partir da incorporação de contribuições da Psicologia Social, o que abriria outra possibilidade de olhar/se pensar a escola. Ainda, as mesmas autoras propõem que pensemos a Psicologia não como um território de autores ou de áreas, mas como campo interdisciplinar. Nesse contexto, destacamos as contribuições tanto das TDIC quanto da chamada Psicologia da Educação Virtual para a construção de novos diálogos nas relações entre Psicologia e Educação.

Há que se considerar que, recentemente, esta área tem recebido maior atenção por parte dos profissionais da Psicologia, tanto em função da rediscussão sobre a proposta da Formação do Professor de Psicologia para o ensino médio (antiga Licenciatura em Psicologia), que deve ser retomada nas universidades federais a partir de 2013 devido a esforços do Conselho Federal de Psicologia (CFP) e da Associação Brasileira de Ensino de Psicologia (ABEP) quanto das atuais transformações ocorridas em relação à inserção das TDIC nos ambientes educacionais (Joly, Silva, \& Almeida, 2012). Mais do que a simples inserção dessas tecnologias, que podem ou não promover mudanças significativas nos processos educacionais, deve-se atentar pelas mudanças instauradas a partir dessa nova forma de dialogar 
com o conhecimento e com a produção de saberes na Psicologia da Educação.

Assim, uma pauta recorrente é justamente a das TDIC, embora a discussão ainda não tenha sido empreendida de modo privilegiado. Um dos apontamentos nesse sentido é o espaço frequentemente reduzido dessas discussões no campo da Psicologia. Por uma análise do último Simpósio da Associação Nacional de Pesquisa e Pós-graduação em Psicologia (ANPEPP), realizado em 2012, as TDIC estão pulverizadas em alguns grupos de trabalho, embora não sejam declaradamente vislumbradas na proposição de um GT. Embora haja grupos específicos em Psicologia Escolar e Educacional e em Psicologia da Educação Matemática, por exemplo, o espaço conferido à discussão das TDIC ainda pode ser ampliado (Borges, Linhares, \& Caixeta, 2011).

Embora a Educação esteja se apropriando de modo mais destacado dessa pauta, o diálogo interdisciplinar ainda é fomentado como forma de ampliar os conhecimentos e as práticas promotoras de desenvolvimento. A partir dessas considerações, podemos pontuar que a Psicologia da Educação tem se aberto progressivamente para a discussão em torno das TDIC, o que será abordado a seguir.

\section{Psicologia da Educação e as TDIC}

As TDIC têm sido recentemente incorporadas aos currículos dos cursos de Psicologia. Entre os marcos dessa incorporação estão o Decreto $n^{\circ}$ 5.622, de 19 de dezembro de 2005, que estabeleceu as diretrizes para a oferta de cursos na modalidade a distância e a Portaria $n^{\circ} 4.059$, de 10 de dezembro de 2004, que autorizou as instituições de ensino superior a introduzirem na organização pedagógica e curricular de seus cursos superiores reconhecidos, a oferta de disciplinas na modalidade semipresencial, definida pela mesma portaria como quaisquer atividades didáticas, módulos ou unidades de ensino-aprendizagem centrados na autoaprendizagem e com a mediação de recursos didáticos organizados em diferentes suportes de informação que utilizem tecnologias de comunicação remota. Outros marcos que podem ser citados foram a criação da Diretoria de Educação a Distância (DED) da Coordenação de Aperfeiçoamento de Pessoal de Nível Superior (CAPES) e da Universidade Aberta do Brasil (UAB). Seus desdobramentos, no entanto, não se aplicam apenas à oferta de disciplinas obrigatórias e optativas, mas da inclusão dessa pauta nas disciplinas especificamente de Psicologia da Educação.

Mas retomando o objetivo central deste estudo, como discutir repercussões das TDIC para a Psicologia da Educação? Alguns apontamentos nesse sentido são oferecidos por Coll e Monereo (2010) no que se refere aos cenários educacionais que questionam em que ponto exatamente começam e terminam as ações de escolas, educadores e psicólogos. Segundo esses autores, os "processos educacionais deverão ocorrer onde existam tecnologias disponíveis e adequadas para mediar entre aprendizes, professores e conteúdos" (p. 39), o que pode significar, na prática, a flexibilização dos espaços como salas de aula, que cada vez mais tornar-se-ão virtualizados, a ocorrência dos processos de ensino-aprendizagem em diferentes ambientes (bibliotecas, museus, exposições, centros de convivência) e a assunção de ambientes globais de aprendizagem em que o desenvolvimento das tecnologias móveis e das redes sem fio possibilitem a ocorrência do aprendizado em qualquer lugar e em diversas situações. A Psicologia da Educação deve refletir acerca dos limites e das potencialidades trazidas por essas mudanças na produção do seu conhecimento.

Em que pese a interação entre as pessoas nas redes sociais, por exemplo, a Psicologia da Educação pode contribuir para a organização didática de conteúdos e formas de interação que podem ser materializadas por meio de ferramentas de aprendizagem. É o que ocorre em muitos ambientes virtuais de aprendizagem (AVA), que têm buscado em teóricos como Vigotski e Bakhtin tanto uma fundamentação teórica como um método para a análise dos processos educacionais e de desenvolvimento nesses AVA (Onrubia, Colomina, \& Engel, 2010; Longhi, Behar, \& Bercht, 2009; Scorsolini-Comin, 2013; Scorsolini-Comin, Inocente, \& Matias, 2009). Na discussão acerca da aprendizagem colaborativa nos AVA, o paradigma da interação é abordado como uma forma de aumentar a probabilidade de ocorrerem interações entre alunos e educadores com maior potencial do ponto de vista dos processos de construção conjunta de significados (Onrubia, Colomina, \& Engel, 2010).

$\mathrm{Na}$ prática, isso equivale a desenvolver nos AVA as explicações elaboradas, apoiar a criação, a manutenção e o progresso da compreensão mútua, bem como a tomada de decisões conjuntas sobre alternativas e pontos de vista, o que envolve diretamente a figura do professor. Esse posicionamento responde a uma das principais críticas feitas a alguns cursos na modalidade a distância, de que a interação seria reduzida a conversas pontuais, a perguntas e respostas, dificultando uma interação mais efetiva e afetiva entre alunos e professores, distanciando-os ainda mais. As propostas de trabalho conjunto, para além de um agrupamento de participantes, propõem o envolvimento dos membros para a execução de uma dada tarefa que não pode ser realizada apenas pela divisão de responsabilidades, mas pelo efetivo contato e compartilhamento de posicionamentos, impressões e reflexões. A convivência no ambiente virtual pode possibilitar a assunção de novos modos de interação e também de trabalho, desenvolvendo competências importantes no contexto da cibercultura, tanto para alunos como para professores.

Em cursos na modalidade a distância, por exemplo, esse paradigma de interação pode ser materializado nas discussões realizadas em fóruns, que funcionam como critério de avaliação da aprendizagem dos alunos, conforme descrito em situações interativas em cursos de formação de executivos (Gameiro, Scorsolini-Comin, Inocente, \& Matias, 2011; Inocente \& Scorsolini-Comin, 2009). Nessas ocasiões, os alunos eram convidados, por meio de uma proposição inicial, a discutir algum ponto de vista acerca de determinado conteúdo de formação que visava a gerar algum nível de 
conflito ou de discordância entre os alunos. Estes, por sua vez, deveriam discutir seus posicionamentos no âmbito do fórum. A análise dessas discussões não se centra no aspecto de resposta correta a uma proposição baseada nos conteúdos estudados, mas justamente no modo como as diferentes argumentações vão se construindo e como as interações vão se articulando, promovendo a aprendizagem e também o desenvolvimento do educando.

Nessas situações interativas, a Psicologia da Educação pode ser utilizada não apenas para explicar os modos como as pessoas interagem, mas como a colaboração vai ocorrendo a partir dos registros escritos dos alunos. A sociabilidade é um dos fatores que emergem nos AVA e que proporcionam interações mais ou menos efetivas, haja vista que está relacionada à facilidade do sujeito em estabelecer relações de amizade e uma postura colaborativa, bem-humorada, sociável e agradável com os colegas (Silva, \& Corradi-Webster, 2011). A chamada competência social para interagir em ambientes colaborativos a distância tem sido estudada como forma de potencializar o aprendizado, de modo que os fóruns de discussão não se resumam a posicionamentos polarizados como certo ou errado, discordo ou discordo, a favor ou contra.

As ferramentas de comunicação (como o fórum) podem ser associadas aos níveis de sociabilidade e liderança, indicando que alunos com níveis mais baixos de competência social para interagir nos AVA devem ser acompanhados e estimulados de maneira diferenciada (Silva, \& Corradi-Webster, 2011). Dessa forma, não se trata de diagnosticar mais aptos e menos aptos em termos de competência social, mas de propor estratégias diferenciadas para que todos possam interagir e se beneficiar desse modo de contato e de formação de comunidades virtuais de aprendizagem.

A mediação realizada pelo professor ou tutor da turma também é um ponto a ser abordado, uma vez que ele acaba contribuindo para fomentar a discussão ou para inserir outras pautas caso as discussões sejam enfraquecidas ao longo do tempo. Ele corrige conceitos empregados de modo equivocado e traz à baila elementos ainda não cotejados pelo grupo. Alguns estudos destacam a necessidade de desenvolver competências no professor para a utilização das TDIC, a fim de que ele possa não apenas empregá-las de modo adequado, como também se posicionar de modo crítico diante dessas tecnologias (Joly, Silva, \& Almeida, 2012; Silva, 2012). Mas a sua atuação não se resume ao domínio da tecnologia, de modo que a sua proximidade afetiva é importante no processo de ensino-aprendizagem, assim como o seu acompanhamento e suas intervenções (Almeida, 2010; Almeida \& Silva, 2011). Essa atuação do professor/tutor pode e deve ser compreendida em maior profundidade, haja vista que muitos dos modelos instrucionais existentes priorizam a sua função gestora, organizadora da aprendizagem e mantenedora dos processos que ocorrem nos AVA.

Nessas situações, são privilegiados aspectos como regras dos cursos, prazos para respostas, tipos de interação permitidos e extensão das respostas. No entanto, sua função extrapola a consideração de um animador de aprendizagem, devendo ser problematizada em termos do acompanhamento pedagógico e das mediações realizadas entre os alunos e os conteúdos estudados.

Mais do que isso, o professor/tutor é um educador que acompanha o aluno em seu processo de desenvolvimento e de aprendizagem nos AVA, podendo propor intervenções pontuais e com objetivos definidos, visando a incrementar, modificar ou potencializar o aprendizado. Ao intervir em um fórum de discussão, seu posicionamento não é neutro, mas destaca saberes e valores expressos não apenas pela posição que ocupa no curso como pelos conhecimentos acerca do conteúdo que detém e que compartilha com os seus alunos em interação, o que dialoga diretamente com as proposições bakhtinianas acerca da linguagem e do dialogismo (Bakhtin, 1999). A sua entoação expressiva, os pontos destacados em sua intervenção e o modo como recupera os conteúdos trazidos pelos alunos revelam formas de compreender o desenvolvimento e os conteúdos de maior relevância.

Sua atuação extrapola a de facilitador, levantando questionamentos ainda não inaugurados pelos alunos (mas presentes no espaço discursivo) e destacando, sempre que possível, pontos de maior relevância para discussão em termos dos objetivos apregoados pelo curso. Retomar os objetivos de aprendizagem é uma das funções que devem ser desenvolvidas constantemente pelos professores/tutores em seus espaços de interlocução com os alunos. Suas ponderações são intencionais e, mais do que isso, colocam o educador em um lugar no qual também pode trazer suas ideias para o círculo de discussão, ampliando as potencialidades dessa ferramenta. Não apenas as falas dos alunos acabam sendo interpenetradas pelos discursos dos professores/tutores, mas também estes acabam se interpenetrando pela experiência de seus diferentes outros em interação. Essa coconstrução conjunta de saberes e práticas produz a chamada aprendizagem colaborativa nos AVA, extensamente discutida no estudo de Onrubia, Colomina e Engel (2010).

Os professores/tutores também são responsáveis pelos feedbacks aos alunos, o que orienta os participantes de um curso a distância, por exemplo, no sentido de direcionar conhecimentos, aprimorar conceitos ou mesmo de potencializar novas aprendizagens. A oferta de feedbacks é o sétimo evento instrucional da teoria de aprendizagem de Robert Gagné (Gagné, Briggs, \& Wagner, 1988) e refere-se a uma devolutiva ou de avaliação do aluno acerca do seu desempenho nas diferentes atividades do curso com o objetivo de proporcionar ao aprendente o reforçamento pelo esforço da aprendizagem (Abreu e Lima, \& Alves, 2011). Os feedbacks especializados (ou seja, com uma avaliação pormenorizada e reflexiva por parte dos professores/tutores) orientam os processos de ensino-aprendizagem e auxiliam os alunos no sentido dos limites e das potencializadas presentes em cada conteúdo. Nesse sentido, observa-se claramente a aplicação de conceitos psicológicos a uma ação educacional, constituindo um novo modo da Psicologia da Educação se posicionar diante desse diálogo. 
Por fim, podemos considerar o desafio da atuação interdisciplinar no que se refere ao emprego das TDIC (Coll, \& Monereo, 2010; Gameiro, \& cols., 2011; Longh, Behar, \& Bercht, 2009), o que deve perpassar desde a construção e o planejamentos dos projetos pedagógicos de ações ofertadas com base nas tecnologias educacionais (como no caso da educação a distância), passando pelos treinamentos dos profissionais que atuarão no projeto (designers, educadores, professores/tutores, gestores, avaliadores), implementação das ações e avaliação das mesmas ao longo do processo. Essa discussão não pertence a um único campo do saber, de modo que a interlocução entre saberes tem sido não apenas a forma mais adequada de conceber e analisar essas ações, como também o modo como naturalmente esses projetos foram sendo desenvolvidos e implementados. A diversidade de formações e experiências desses profissionais têm possibilitado a construção de um campo de atuação híbrido e em permanente transformação.

Desse modo, ao aproximarmos as TDIC da Psicologia da Educação, há que se destacar que estamos falando não de uma Psicologia da Educação clássica, tradicional e comprometida com os problemas investigados há mais de 40 anos no contexto brasileiro, mas de problemáticas recentes, de questões ainda em formulação, de propostas que têm sido duramente criticadas pelo seu caráter considerado mercantilista e de distanciamento entre alunos e professores (Patto, 2013), de desafios que ainda serão inscritos nas pesquisas vindouras. Trata-se de uma Psicologia da Educação em escrita e em acontecimento, em que o emprego de conceitos advindos da Educação e da Psicologia mostram-se importantes para o desenvolvimento de respostas novas a desafios novos.

O cenário de atuação desse campo ainda está em delimitação, de modo que a pesquisa na área deve ser fomentada tendo em vista as mudanças, os entraves e os diálogos necessários. Uma premissa que pode orientar os pesquisadores é a de que as tecnologias educacionais devem estar a serviço do aprendizado e da prática pedagógica, sendo que esta deve ser permanentemente apreciada de modo crítico. A Psicologia da Educação, para além dos tradicionais estudos com foco no indivíduo, suas competências e desajustes, deve abarcar o contexto da cibercultura, das interações realizadas por meio de redes sociais, do maior acesso à internet e à tecnologia móvel por parte de alunos e professores, do papel dos grupos nos processos de ensino-aprendizagem e da função essencial do professor. É na tentativa de cotejar essas características que os novos estudos podem se apresentar.

\section{Considerações finais}

As repercussões das TDIC para a Psicologia da Educação ainda estão sendo escritas e discutidas tanto por educadores e psicólogos como por diversos outros profissionais envolvidos no contexto contemporâneo das tecnologias educacionais. Neste estudo, foram destacadas potencialidades da Psicologia da Educação para a refle- xão em torno da interação, da mediação dos professores/ tutores, da construção de práticas em ambientes virtuais de aprendizagem, bem como de diretrizes para a formação de profissionais para atuarem em contextos como os da EAD. Outras repercussões podem e devem ser trazidas à baila em futuras investigações.

A avaliação de ações educacionais ofertadas a distância, por exemplo, podem ser um mote para a atuação dos profissionais da Psicologia da Educação (Scorsolini-Comin, 2013). Como os saberes já construídos podem auxiliar nesse processo? Como a Psicologia da Educação pode incorporar essas reflexões e manter uma identidade enquanto área de interface entre Psicologia e Educação? Essas questões são prementes e não podem ser negligenciadas pelos profissionais da área, muito menos pelos pesquisadores. As pautas aqui discutidas podem e devem dar origem a estudos conduzidos por pesquisadores comprometidos com a produção do conhecimento científico e que ganhem o devido espaço em comunidades acadêmicas com a ANPed e a ANPEPP, por exemplo, isso pensando estritamente no contexto nacional de produção.

Para pensar o futuro da Psicologia da Educação, Maluf (2010) faz uma projeção afirmando que essa ciência deve produzir conhecimento útil, aprofundando a relação com a prática para a geração de bem-estar para indivíduos e grupos, nas diferentes culturas e na domesticação da tecnologia para fazê-la servir ao fator humano. Ao empregar a expressão domesticação da tecnologia, utiliza a concepção de Lévy (2010) sobre o domínio da técnica, de modo que esta não seja determinante, mas condicionante do desenvolvimento na contemporaneidade. No entanto, para além da domesticação, que pressupõe a dominação sobre algo ou alguém, há que se incorporar as TDIC como uma pauta em permanente discussão.

$\mathrm{Na}$ cibercultura, as reflexões podem girar em torno de como promover uma aproximação entre as características dos ciberespaços, das redes sociais e da web semântica e os conceitos trabalhados pela Psicologia da Educação, por exemplo, criando espaços de interlocução que podem ou não receber novas nomenclaturas (como Psicologia da Educação Virtual), mas que devem conservar o espírito instaurado pelas sociedades do conhecimento e da informação: de que os conhecimentos não são estanques e de que o diálogo continua inconcluso, por ser feito, por ser modificado, aprimorado e desenvolvido de modo perene, tal como anunciado no pensamento bakhtiniano.

\section{Referências}

Abreu-e-Lima, D. M., \& Alves, M. N. (2011). O feedback e sua importância no processo de tutoria a distância. Pro-Posições, 22(2), 189-205.

Almeida, M. E. B. (2010). Transformações no trabalho e na formação docente na educação a distância on-line. Em Aberto, 23(84), 6777 . 
Almeida, M. E. B., \& Silva, M. G. M. (2011). Currículo, tecnologia e cultura digital: Espaços e tempos de Web Currículo. Revista e-curriculum, 7(1). Recuperado: 28 jun. 2013. Disponível: http:// revistas.pucsp.br/index.php/ curriculum/article/view/5676.

Bakhtin, M. M. (1999). Marxismo e filosofia da linguagem. (M. Lahud, \& F. Frateschi, Trad.). São Paulo: Hucitec. (Original publicado em 1929).

Barbosa, D. R., \& Souza, M. P. R. (2012). Psicologia Educacional ou Escolar? Eis a questão. Psicologia Escolar e Educacional, 16(1), 163-173.

Bezerra, G. F., \& Araújo, D. A. C. (2012). Psicologia da Educação: Uma disciplina em crise no pós-construtivismo. Psicologia Escolar e Educacional, 16(1), 143-151.

Borges, F. T., Linhares, R. N., \& Caixeta, J. E. (2011). O professor de EAD: Significados e contradições. In R. N. Linhares, \& S. L. Ferreira (Org.), Educação a Distância e as tecnologias da inteligência: Novos percursos de formação e aprendizagem (pp. 83-114). Maceió: EdUFAL.

Castells, M. (2001). La galaxia internet. Barcelona: Areté.

Coll, C., \& Monereo, C. (2010). Apresentação. Em Psicologia da Educação Virtual: Aprender e ensinar com as tecnologias da informação e da comunicação (pp. 9-14). (N. Freitas, Trad.). Porto Alegre: Artmed.

Coll, C., Palacios, J., \& Marchesi, A. (Orgs.). (1996). Desenvolvimento psicológico e educação: Psicologia da Educação. Vol. 2. Porto Alegre: Artes Médicas.

Carvalho, D. C., Facci, M. G., \& Barroco, S. M. S. (2010). A produção científica do GT de Psicologia da Educação da ANPEd e a apropriação de teorias psicológicas. Psicologia da Educação, 31, 79-104.

Decreto $n^{\circ}$ 5.622. (2005,19 de dezembro). Regulamenta o art. 80 da Lei no 9.394, de 20 de dezembro de 1996, que estabelece as diretrizes e bases da educação nacional. Brasília, DF: Presidência da República. Recuperado: 02 out. 2012. Disponível: https:// www.planalto.gov.br /ccivil_03/_Ato2004-2006/2005/Decreto/ D5622compilado.htm.

Gagné, R. M., Briggs, L. J., \& Wagner, W. W. (1988). Principles of instructional design. ( $3^{\mathrm{a}}$ ed.). Nova York: Holt, Rinehart \& Winston.

Gameiro, F. J., Scorsolini-Comin, F., Inocente, D. F., \& Matias, A. B. (2011). Avaliação de tecnologias educacionais em cursos a distância. Revista Digital de Biblioteconomia e Ciência da Informação, 8(2), 88-113.

Gatti, B. (2010). Psicologia da Educação: Conceitos, sentidos e contribuições. Psicologia da Educação, 31, 7-22.
Inocente, D. F., \& Scorsolini-Comin, F. (2009). Ambientação em Educação a Distância (EAD): Uma aproximação inicial. Ribeirão Preto: Instituto de Ensino e Pesquisa em Administração.

Joly, M. C. R. A., Silva, B. D., \& Almeida, L. S. (2012). Avaliação das competências docentes para utilização das tecnologias digitais da comunicação e informação. Currículo Sem Fronteiras, 12(3), 8396.

Lévy, P. (2010). Cibercultura. $3^{a}$ ed. (C. I. Costa, Trad.). São Paulo: 34.

Lipovetsky, G. (2007). A felicidade paradoxal: Ensaios sobre a sociedade de hiperconsumo. (M. L. Machado, Trad.). São Paulo: Companhia das Letras.

Longh, M. T., Behar, P. A., \& Bercht, M. (2009). A busca pela dimensão afetiva em ambientes virtuais de aprendizagem. Em P. A. Behar (Org.). Modelos pedagógicos em educação a distância (pp. 204231). Porto Alegre: Artmed.

Maluf, M. R. (2010). Psicologia da educação: Perspectivas de futuro. Psicologia da Educação, 31, 29-34.

Mialaret, G. (1999). Psicologia da Educação. Lisboa: Instituto Piaget. (Coleção Epigênese, Desenvolvimento e Psicologia).

Moreira, A. F. B., \& Kramer, S. (2007). Contemporaneidade, educação e tecnologia. Educação \& Sociedade, 28(100), 1037-1057.

Onrubia, J., Colomina, R., \& Engel, A. (2010). Os ambientes virtuais de aprendizagem baseados no trabalho em grupo e na aprendizagem colaborativa. Em C. Coll, \& C. Monereo (Orgs.). Psicologia da Educação Virtual: Aprender e ensinar com as tecnologias da informação e da comunicação (pp. 208-225). (N. Freitas, Trad.). Porto Alegre: Artmed.

Patto, M. H. S. (2013). O ensino a distância e a falência da educação. Educação e Pesquisa, 39(2), 303-318.

Pereira, L. D. (2009). Mercantilização do ensino superior, educação a distância e Serviço Social. Revista Katálysis, 12(2), 268-277.

Portaria $n^{\circ}$ 4.059. (2004, 10 de dezembro). Trata da oferta de disciplinas na modalidade semi-presencial em cursos superiores já reconhecidos. Brasília, DF: Diário Oficial da União. Recuperado: 02 out. 2012. Disponível: http://meclegis.mec.gov.br/documento/ view/id/89.

Rother, E. T. (2007). Revisão sistemática x revisão narrativa. Acta Paulista de Enfermagem, 20(2), 5-6.

Schlindwein, L. M., \& Cordeiro, M. H. B. V. (2010). O Grupo de Trabalho Psicologia da Educação e sua produção entre os anos de 2005 e 2009. Psicologia da Educação, 31, 53-64.

Scorsolini-Comin, F. (2013). Avaliação dos processos de ensinoaprendizagem em ações educacionais ofertadas a distância. 
Temas em Psicologia (Ribeirão Preto), 21(2), 335-346.

Scorsolini-Comin, F., Inocente, D. F., \& Matias, A. B. (2009). Análise de ferramentas de interação e comunicação em ambiente virtual de aprendizagem a partir de contribuições de Bakhtin. Educação: Teoria e Prática, 19(32), 173-189.

Silva, M. (Org.) (2012). Formação de professores para docência online. São Paulo, SP: Edições Loyola.

Silva, E. C., \& Corradi-Webster, C. M. (2011). Competência social para interagir em ambientes virtuais de aprendizagem. Investigación y Educación en Enfermería, 29(1), 97-102.
Witter, C. (2005). Produção científica e educação: Análise de um periódico nacional. Em G. P. Witter (Org.). Metaciência e Psicologia (pp. 199-215). Campinas, SP: Alínea.

Zuin, A. A. S. (2006). Educação a distância ou educação distante? O programa Universidade Aberta do Brasil, o tutor e o professor virtual. Educação \& Sociedade, 27(96), 935-954.

\section{Sobre o autor}

Fabio Scorsolini-Comin (scorsolini_usp@yahoo.com.br)

Doutor em Psicologia pela Universidade de São Paulo. Professor Adjunto do Departamento de Psicologia da Universidade Federal do Triângulo Mineiro. 